responsible has proved

difficult.

A team led by Stephen Bentley and Julian Parkhill, at the Wellcome Trust Sanger Institute in Hinxton, UK, analysed the genomes of 3,701 samples of S. pneumoniae collected from carriers in a refugee camp in Thailand and from patients in Massachusetts clinics.

The authors searched for regions of the genome that differed between bacteria resistant to $\beta$-lactam antibiotics (such as penicillin) and those still susceptible to them. They found 301 DNA variations in 51 regions linked to drug resistance, including novel genes as well as those involved in building the cell wall, the target of the $\beta$-lactams.

PLoS Genet. 10, e1004547 (2014)

\section{IMAGING \\ Seeing through a mouse skull}
Glowing nanotubes have allowed researchers to peer through a mouse's skull and examine its living brain in real time.
Calvin Kuo and Hongjie Dai of Stanford University in California and their colleagues injected fluorescent molecules based on carbon nanotubes into the tails of mice. The nanotubes were then carried around in the animals' bloodstreams and when lasers were shone onto the rodents' skulls, the molecules gave off near-infrared light (pictured) that was visible through the bone. This allowed the researchers to image blood moving through the brain to a depth of more than 2 millimetres and to detect

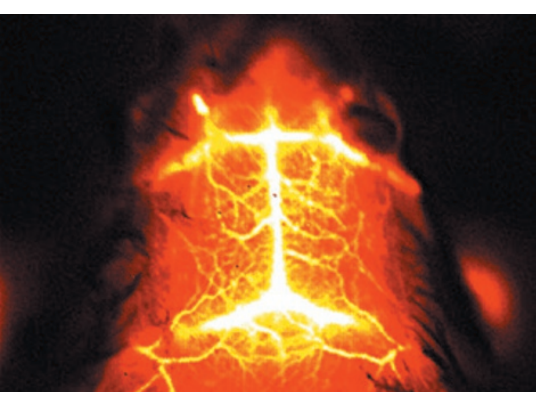

obstructed arteries. However, the method might not be usable in humans because of our thicker skulls.

Nature Photon. http://doi.org/ t2z (2014)

\section{SEISMOLOGY}

\section{From earthquakes to icequakes}

Big earthquakes on land can trigger small distant 'icequakes' in the Antarctic ice sheet.

At magnitude 8.8, the 2010

Maule earthquake in Chile was the largest quake in the Southern Hemisphere for half a century. Zhigang Peng at the Georgia Institute of Technology in Atlanta and his colleagues hunted for traces of it at seismic stations across Antarctica.

They discovered high-frequency shaking representing small icequakes, with waves of tremors appearing in the kilometrethick ice sheet that covers the frozen continent. These seemed to be triggered by the lower-frequency rumble stemming from the Chilean event, and represent the first evidence of links between quakes in the solid earth and in the cryosphere.

Nature Geosci. http://dx.doi. org/10.1038/ngeo2212 (2014)

\section{STEM CELLS}

\section{Fresh growth from elderly cells}

Human skin cells can be reprogrammed into neural cells that form synapses with neurons in severed spinal cords in rats.

A team led by Paul Lu and Mark Tuszynski at the University of California San Diego in La Jolla took skin fibroblasts from an 86-year-old man, converted them in culture into induced pluripotent stem cells (iPS cells) and then into neural stem cells, and grafted these cells into two-week-old immunodeficient rats whose spinal cords were damaged at the neck. Three months later, the stem cells had grown into

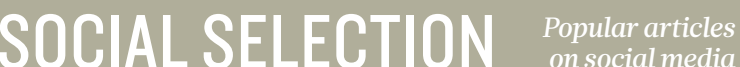

\section{Clash over the Kardashians of science}

Here's a novel approach for getting an article noticed: put 'Kardashian' in the title. A paper that compared Twitter-using researchers to the celebrity Kim Kardashian incited a backlash on social media.

Neil Hall, a genomics researcher at the University of Liverpool, UK, introduced a metric called the Kardashian Index, or K value. This is calculated by dividing a researcher's number of Twitter followers by the number of scientific citations he or she has. The K value supposedly identifies scientists whose visibility exceeds their contributions somewhat like a certain socialite, Hall suggests. The article was intended as satire, but not everyone was amused. "This paper suggests only highly cited scientists deserve a large Twitter following, \& everyone else should shut up," tweeted Katie Mack, an astrophysicist at the University of Melbourne in Australia. Genome Biol. 15, 424 (2014)

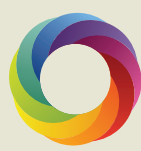

Based on data from altmetric.com Altmetric is supported by Macmillan Science and Education, which owns Nature Publishing Group.

DNATURE.COM

For more on popular papers: go.nature.com/hqeqwb neurons that projected axons along the whole length of the rat spinal cord, even extending into the brain. Unlike similar experiments with neurons derived from embryonic stem cells, these iPS-cell-derived neurons did not restore movement in the rats' limbs, perhaps as a result of scar tissue that formed at the injury site. Neuron http://doi.org/t36 (2014)

\section{MICROBIOLOGY \\ Ecosystems afloat in asphalt}

Water droplets suspended in the world's largest tar 'lake' are teeming with diverse ecosystems of bacteria and methane-producing microorganisms, despite the inhospitable living conditions.

Droplets just a few microlitres in volume that were isolated from Pitch Lake (pictured), a huge tar pit on the island of Trinidad, contain a menagerie of bacteria and archaea, report Rainer Meckenstock at the Helmholtz Zentrum in Munich, Germany, and his colleagues.

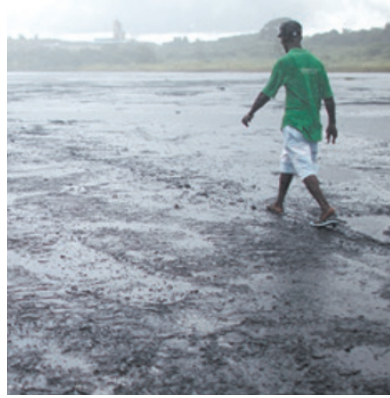

They used DNA sequencing to reveal that multiple species work together to break down the oil surrounding the water droplets, which are thought to originate deep underground.

These microhabitats could be an unrecognized factor in the biodegradation of large volumes of oil, the authors suggest.

Science 345, 673-676 (2014)

For a longer story on this research, see go.nature.com/odleal

\section{$\rightarrow$ NATURE.COM}

For the latest research published by Naturevisit:

www.nature.com/latestresearch 